\title{
Survival and Quality of Life of Patients after Rectal Cancer Surgery in a Low-Income Country: A Study in Cameroon, Sub-Saharan African Region
}

\author{
Guy Aristide Bang 1,2*, Eric Patrick Savom ${ }^{1,3}$, Georges Bwelle Moto ${ }^{1,4}$, \\ Julienne Yambassa Fayam², Yannick Mahamat Ekani Boukar4, \\ Ousmana Oumarou ${ }^{4}$, Arthur Essomba ${ }^{1,2}$, Maurice Aurélien Sosso ${ }^{1}$ \\ ${ }^{1}$ Department of Surgery and Subspecialties, Faculty of Medicine and Biomedical Sciences, University of Yaoundé I, Yaoundé, \\ Cameroon \\ ${ }^{2}$ Surgery Unit, Yaoundé University Teaching Hospital, Yaoundé, Cameroon \\ ${ }^{3}$ Surgery Unit, Yaoundé General Hospital, Yaoundé, Cameroon \\ ${ }^{4}$ Digestive Surgery Unit, Yaoundé Central Hospital, Yaoundé, Cameroon \\ Email: `guyaristidebang@yahoo.fr, esavom@yahoo.fr, gbwelle@gmail.com, yjuliennediane@yahoo.com, \\ boukaryoussouf@gmail.com,drousmana@gmail.com,artgessomba@gmail.com,sossomaurice@yahoo.fr
}

How to cite this paper: Bang, G.A., Savom, E.P., Moto, G.B., Fayam, J.Y., Boukar, Y.M.E., Oumarou, O., Essomba, A. and Sosso, M.A. (2021) Survival and Quality of Life of Patients after Rectal Cancer Surgery in a Low-Income Country: A Study in Cameroon, Sub-Saharan African Region. Surgical Science, 12, 261-273. https://doi.org/10.4236/ss.2021.128027

Received: July 14, 2021

Accepted: August 20, 2021

Published: August 23, 2021

Copyright $\odot 2021$ by author(s) and Scientific Research Publishing Inc. This work is licensed under the Creative Commons Attribution International License (CC BY 4.0).

http://creativecommons.org/licenses/by/4.0/ (c) (i) Open Access

\begin{abstract}
Background: Survival of patients after rectal cancer surgery as well as their quality of life (QoL) has been little studied in Africa and never in our country in particular. Methods: We conducted a cross-sectional multicentre study in Yaoundé (Cameroon). We reviewed operating reports of the selected departments to identify patients operated from January 2010 to December 2019 for a rectal cancer. The outcome of patients enrolled had to be known until December 2020. Patients who were alive were contacted to evaluate their QoL using the EORTC QLQ C30 (European Organization for Research and Treatment of Cancer QoL questionnaire). Results: During the study period, rectal cancer was ranked $4^{\text {th }}$ within the digestive cancers. We included 68 patients; their mean age was 49.74 years and $41.18 \%$ were under 45 . The sex ratio was 1.19 in favour of males. The tumour was mainly located in the lower rectum (45.6\%). The main surgical procedure implemented was abdomino-perineal resection $(42.6 \%)$. Forty-one patients died, giving a mortality rate of $60.29 \%$. The mean survival time was 13 months. The 5-year survival rate for the 32 patients operated from January 2010 to December 2015 was $21.87 \%$. The overall QoL of the 27 living patients was good with a mean of $62.346 \pm$ 15.907. Sexual complications and urinary disorders were found in $40.74 \%$ and $14.81 \%$ of patients, respectively. Conclusion: There is a low hospital incidence
\end{abstract}


of rectal cancer in our context. The 5-year survival after rectal cancer surgery is poor while the QoL of living patients is good.

\section{Keywords}

Rectal Cancer, Survival, Quality of Life, Cameroon

\section{Introduction}

Rectal cancer is one of the most frequent human malignant neoplasms. It represents $29.3 \%$ of cancers of the large intestine [1]. Rectal cancers are usually considered as a part of colorectal cancers (CRC) in related epidemiological studies. According to GLOBOCAN 2018, over 1.8 million new CRC cases and 881,000 related deaths were estimated to occur in 2018, accounting for about 1 in 10 cancer cases and deaths; overall, CRC ranked third in terms of incidence of cancers but second in terms of cancer related mortality [2].

CRC incidence rate is about 3 -fold higher in developed versus developing countries; however, the survival rate is lower in limited settings [2] [3]. Possible explanations are: delayed diagnosis with predominance of advanced stages [4] [5] [6] [7] [8], insufficient hospitals' technical platform [5] [9] [10] and poverty with absence of a national health insurance policy [9]. Some authors thus highlighted the "medical fracture" between recommendations of learned societies and the management of rectal cancers in our (poor) setting [10]. Rectal cancer in our environment is also characterized by a high proportion of young patients [4] [5] [6] [8] [11] suggesting a possible involvement of genetic factors [12].

The treatment of rectal cancer is based on several therapeutic modalities among which surgery occupies a prominent place. However, its association with neoadjuvant or adjuvant treatments (chemotherapy and/or radiotherapy) improves survival [13]. In Black Africa, accessibility to chemotherapy and radiotherapy is low due to the high cost and scarcity of dedicated services [9] [10] [14] [15] [16]. In this context, surgery is therefore often the only therapeutic modality implemented [14] [17].

Rectal cancer surgery presents challenges such as the necessity for extensive yet precise dissection and the proximity of major anatomic structures, in a limited (pelvic) space [18]. A morbidity of $30 \%-50 \%$ has been reported after rectal cancer surgery [19] [20]; urinary and sexual complications are found in $7 \%$ $27 \%$ [21] [22] and 6.3\% - 100\% of cases [23] [24], respectively. All these complications may affect patients' quality of life (QoL).

To the best of our knowledge, no study has been carried out on the outcome of patients after rectal cancer surgery in our country; in particular, patients' postoperative QoL has been little studied in black Africa and never in our country. Therefore, we undertook this study with the aim of determining the survival and QoL of patients who had surgery for rectal cancer in our environment. 


\section{Methods}

\subsection{Study Design and Setting}

We conducted a cross-sectional multicentre study in three hospitals in Yaoundé (capital city of Cameroon): Yaoundé University Teaching Hospital, Yaoundé Central Hospital and the National Social Insurance Fund Health Centre of Yaoundé. The selected hospitals were university hospitals with a department of digestive surgery.

\subsection{Study Participants}

We reviewed operating reports of the selected departments to identify patients operated from January 2010 to December 2019 for a rectal cancer. Their files were consulted to complete the standardized data collection form. Information on demographic data, history, clinical presentation, histologic findings, management, and outcome variables were collected. The outcome of patients enrolled had to be known until December 2020; thus, each patient had a follow-up period of at least one year. Duplicates, unusable files and files of patients lost to follow-up at the time of the study were excluded. The preoperative diagnosis of rectal cancer was made on rectal biopsies obtained after proctoscopy or colonoscopy.

Patients who were alive were then contacted; after obtaining their informed consent or those of their parents/guardians, we met them at their home or in a consultation cubicle. An interview was conducted to evaluate their postoperative QoL using the EORTC QLQ C30 (European Organization for Research and Treatment of Cancer QoL questionnaire) version 3. Every patient completed the questionnaire individually. Validated English and French (Europe) translations of EORTC QLQ C30 were used, since our country is bilingual (French and English). If necessary, some items were explained to the participants on local language. Components items of The QLQ-C30 (version 3.0) are: global health status, 5 functional scales (physical, role, social, cognitive and emotional), 3 symptom scales (fatigue, nausea and vomiting, pain) and 5 independent items (dyspnea, sleep disturbance, appetite loss, constipation, financial impact).

\subsection{Statistical Analysis}

Data analysis was conducted using IBM SPSS software for Windows, version 23.0 (IBM Corp., Armonk, N.Y., USA). Means and Standard Deviations were calculated for parametric data and categorical variables were reported as counts and percentages. Kaplan-Meier survival analysis was used to build the survival curve of the study population and Cox proportional hazard regression to identify independent predictors of survival. Considering the EORTC QLQ C30, at least $75 \%$ of items completed by patients were considered assessable in the current study, and missing data were handled as instructed in the EORTC scoring manual. Completed questionnaires were scored according to the developers' in- 
structions. All of the scales measures range in score from 0 - 100, and a high scale score represents a higher response level. Thus, a high score for the global health status represents a high QoL, a high score for a functional scale represents a healthy level of functioning and a high score for a symptom scale/independent item represents a high level of symptomatology/problems.

\section{Results}

During the study period, we identified 631 cases of digestive tumours, including 105 rectal cancers $(16.6 \%)$. Rectal tumours were ranked $4^{\text {th }}$, after colonic (26.6\%), pancreatic (23.5\%) and gastric (21.6\%) cancers. Of the 105 rectal tumours registered, 68 met our inclusion criteria.

\subsection{Clinical Epidemiology}

There were 37 men (54.4\%) with a sex ratio of 1.19 . The mean age was $49.74 \pm$ 16.929 years (range, 18 - 90 years). Twenty-eight patients (41.18\%) were under 45 years old. At the time of diagnosis, the commonest signs/symptoms were: altered general condition $(n=65,95.6 \%)$, abdominal pain $(n=65,95.6 \%)$ and rectal bleeding $(\mathrm{n}=51,75 \%)$. Symptoms and clinical signs present at diagnosis are summarized in Table 1.

At endoscopy ( $\mathrm{n}=68,100 \%)$, the tumour was mainly located in the lower rectum $(\mathrm{n}=31,45.6 \%)$, circumferential $(\mathrm{n}=31,45.6 \%)$ and budding $(\mathrm{n}=60$, $88.23 \%$ ). The endoscopic characteristics are summarized in Table 2.

At diagnosis, the tumor was locally advanced or metastatic in 13 cases $(19.12 \%)$. Metastatic sites were: obturator and external iliac nodes $(n=12)$, liver $(n=10)$, bladder $(n=7)$, lung $(n=6)$, peritoneum $(n=2)$, bone $(n=2)$ and vagina $(n=2)$. No MRI had been performed.

Table 1. Clinical epidemiology features of the study population.

\begin{tabular}{ccc}
\hline Variables & Frequencies & Percentages \\
\hline Male & 37 & \\
Female & 31 & 54.4 \\
\hline & Age in years & 45.6 \\
\hline$[15-25]$ & 3 & 4.4 \\
{$[25-35]$} & 9 & 13.2 \\
{$[35-45]$} & 16 & 23.5 \\
{$[45-55]$} & 12 & 17.6 \\
{$[55-65]$} & 15 & 22.1 \\
{$[65-75]$} & 8 & 11.8 \\
{$[75-85]$} & 4 & 5.9 \\
{$[85-95]$} & 1 & 1.5 \\
\hline
\end{tabular}




\section{Continued}

\begin{tabular}{ccc}
\hline & Clinical symptoms/signs & \\
\hline Abdominal pain & 65 & 95.6 \\
Vomiting & 17 & 25.0 \\
Constipation & 47 & 69.1 \\
Diarrhea & 23 & 33.8 \\
Alternating diarrhea/constipation & 19 & 27.9 \\
Anal bleeding & 51 & 75.0 \\
Anal pain & 3 & 4.4 \\
Rectal syndrome & & \\
Indentations & 22 & 32.4 \\
Tenesmus & 25 & 36.8 \\
False needs & 9 & 13.2 \\
Alterated general condition & 65 & 95.6 \\
Abdominal distension & 13 & 19.1 \\
Ascites & 3 & 4.4 \\
Clinical anemia & 21 & 30.9 \\
\hline
\end{tabular}

Table 2. Endoscopic findings.

\begin{tabular}{|c|c|c|}
\hline Variables & Number & Percentage \\
\hline \multicolumn{3}{|c|}{ Type of endoscopy } \\
\hline Rectosigmoidoscopy & 40 & 58.8 \\
\hline Total colonoscopy & 28 & 41.2 \\
\hline \multicolumn{3}{|c|}{ Tumor site } \\
\hline Lower rectum & 31 & 45.6 \\
\hline Middle rectum & 21 & 30.9 \\
\hline High rectum & 16 & 23.5 \\
\hline \multicolumn{3}{|c|}{ Location of the tumor } \\
\hline Circumferential & 26 & 38.2 \\
\hline Anterior & 23 & 33.8 \\
\hline Posterior & 5 & 7.3 \\
\hline Left side & 8 & 11.8 \\
\hline Right side & 6 & 8.8 \\
\hline \multicolumn{3}{|c|}{ Macroscopic aspect } \\
\hline Budding appearance & 29 & 42.2 \\
\hline Ulcerative budding appearance & 31 & 45.6 \\
\hline Ulcerative infiltration & 7 & 10.3 \\
\hline Stenosing aspect & 23 & 33.8 \\
\hline Hemorrhagic lesion & 14 & 20.6 \\
\hline
\end{tabular}


Only 14 patients $(20.6 \%)$ had received a neoadjuvant chemotherapy. Surgical procedures implemented were: abdominoperineal resection $(n=29,42.6 \%)$, anterior rectal resection $(n=24,35.3 \%)$, Hartmann's operation $(n=8,11.8 \%)$ and diverting colostomy $(\mathrm{n}=7,10.3 \%)$. Only 15 patients $(22.01 \%)$ had an adjuvant therapy; it was chemotherapy in 14 cases and radiotherapy in 1 case.

On pathology, the different histologic types were: lieberkuhnian adenocarcinoma $(\mathrm{n}=56,82.4 \%)$ and mucous colloid carcinoma $(\mathrm{n}=12,17.6 \%)$. The tumor was at TNM stage I in 21 cases (30.88\%), stage IIA and IIB in 4 cases $(5,88 \%)$, stage IIC in 5 cases $(7.36 \%)$, stage III in 25 cases $(36.8 \%)$ an stage IV in 13 cases $(\mathrm{n}=19.12 \%)$. The cancer was well differentiated in only 18 cases $(26.5 \%)$. In the 61 patients who had a resection, it was of type R0 in the majority of cases $(n=52,85.24 \%)$ and $R 1$ for the rest. An average of 10 lymph nodes was present on the surgical specimen (range, 6 - 17).

Thirty-one patients $(45.6 \%)$ presented postoperative complications among which: surgical site infection $(\mathrm{n}=22,32.4 \%)$, enterocutaneous fistula $(\mathrm{n}=10$, $14.7 \%)$, respiratory distress $(n=8,11.8 \%)$, prolonged ileus $(n=8,11.8 \%)$, postoperative peritonitis $(n=1,1.5 \%)$ and evisceration $(n=1,1.5 \%)$.

\subsection{Survival}

Out of the 68 patients in our study, the 30-day mortality was of $4.41 \%(\mathrm{n}=3)$; one of these deaths was related to stercoral peritonitis due to anastomotic fistula after anterior resection of the rectum and the two others to pulmonary embolism.

The overall mortality showed that 41 patients died giving a mortality rate of $60.29 \%$. The mean survival time was 13 months. The 5 -year survival rate for the 32 patients operated from January 2010 to December 2015 was $21.87 \%(n=7)$. Figure 1 shows the Kaplan-Meier curve of overall survival of our patients.

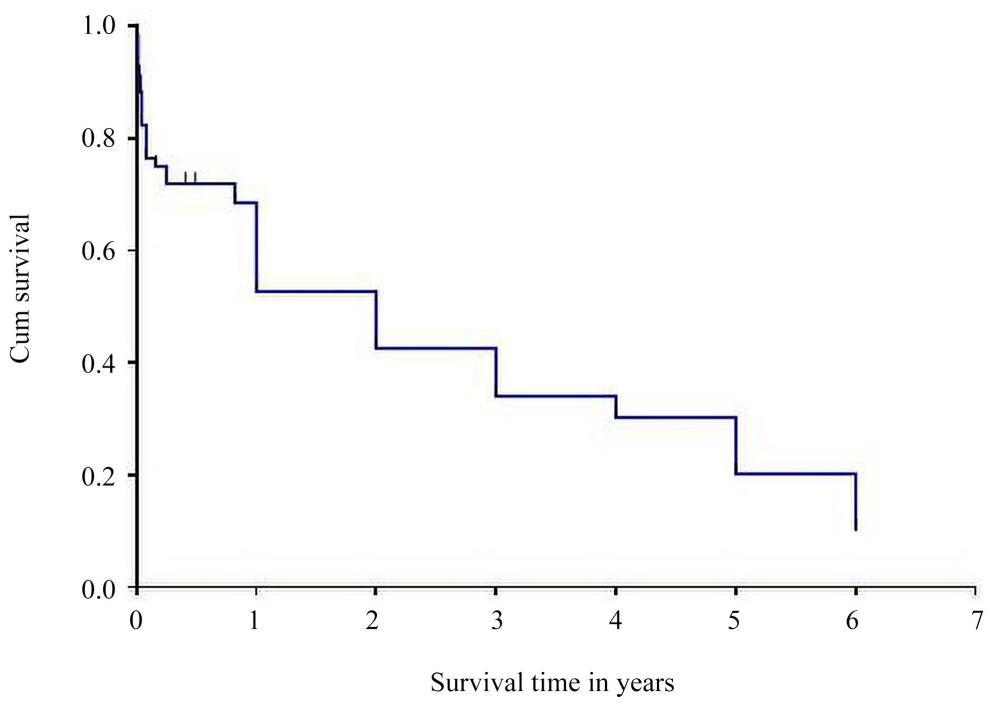

Figure 1. Kaplan-Meier curve of patients' overall survival after rectal cancer surgery. 
On univariate cox proportional regression analysis (Table 3), 11 variables were associated with diminished overall survival: lack of formal education ( $\mathrm{p}=$ $0.003)$, tenesmus $(\mathrm{p}=0.048)$, anal pain $(\mathrm{p}=0.028)$, hepatomegaly $(\mathrm{p}=0.003)$, posterior localisation of the tumor $(\mathrm{p}=0.038)$, postoperative chemotherapy $(\mathrm{p}=$ $0.009)$, surgical site infection $(\mathrm{p}=0.001)$, enterocutaneaous fistula $(\mathrm{p}=0.049)$, postoperative bowel obstruction $(\mathrm{p}=0.007)$ and postoperative respiratory distress $(\mathrm{p}=0.001)$.

On multivariable analysis (Table 4), variables independently associated with overall survival included: no schooling $(\mathrm{p}=0.001)$, tenesmus $(\mathrm{p}=0.037)$, postoperative chemotherapy $(p=0.015)$, surgical site infection $(p=0.003)$ and postoperative bowel obstruction $(\mathrm{p}=0.028)$.

\subsection{QoL}

The overall QoL of the 27 living patients was good with a mean of $62.346 \pm$ 15.907. Social function was the most affected item in the functioning scales. Pain and fatigue were the most common symptoms with a score of $33.33 \pm 35.417$ and $33.333 \pm 20.884$, respectively. Rectal cancer had a significant negative impact on the finances of almost all patients with a median score of $97.531 \pm 8.896$. Table 5 presents the normalized score of patients according to EORTC-QLQ C30. QoL of patients who had abdominoperineal excision wasn't poor compared to those who had anterior rectal resection $(\mathrm{p}=0.06)$.

Table 3. Univariated Cox regression for factors associated to diminished survival.

\begin{tabular}{|c|c|c|c|c|}
\hline Variables & $\begin{array}{c}\text { Deceased patients } \\
\mathrm{N}(\%)\end{array}$ & $\begin{array}{c}\text { Alive patients } \\
\mathrm{N}(\%)\end{array}$ & OR (95\% IC) & P-value \\
\hline No schooling & $6(85.7)$ & $1(14.3)$ & $3.8(1.6-9.3)$ & 0.003 \\
\hline Tenesmus & $11(44)$ & $14(56)$ & $0.5(0.2-0.9)$ & 0.048 \\
\hline Anal pain & $3(100)$ & $5(41.7)$ & $1.01(0.4-2.3)$ & 0.028 \\
\hline Hepatomegaly & $2(100)$ & $0(0)$ & $10.1(2.2-46.5)$ & 0.003 \\
\hline Posterior tumoral localisation & $3(100)$ & $0(0)$ & $3.5(1.1-11.6)$ & 0.038 \\
\hline Postoperative chemotherapy & $2(14.3)$ & $12(85.7)$ & $0.1(0.04-0.6)$ & 0.009 \\
\hline Surgical site infection & $18(81.8)$ & $4(8.2)$ & $3.8(1.9-7.5)$ & $<0.001$ \\
\hline Enterocutaneous fistula & $7(70)$ & $3(30)$ & $2.4(1.01-5.5)$ & 0.049 \\
\hline Postoperative bowel obstruction & $6(75)$ & $2(25)$ & $3.4(1.4-8.4)$ & 0.007 \\
\hline Postoperative respiratory distress & $1(100)$ & $0(0)$ & $5.5(2.3-13.1)$ & $<0.001$ \\
\hline
\end{tabular}

Table 4. Multivariated Cox regression for factors associated to diminished survival.

\begin{tabular}{ccc}
\hline Variables & OR (95\% IC) & P-value \\
\hline No schooling & $7.9(2.7-23.4)$ & $<0.001$ \\
Tenesmus & $0.5(0.2-0.9)$ & 0.037 \\
Postoperative chemotherapy & $0.2(0.04-0.7)$ & 0.015 \\
Surgical site infection & $3.2(1.5-6.7)$ & 0.003 \\
Enterocutaneous fistula & $0.9(0.3-2.4)$ & 0.773 \\
Postoperative bowel obstruction & $2.8(1.1-7.1)$ & 0.028 \\
\hline
\end{tabular}


Table 5. Patient's quality of life evaluation according to EORTC-QLQ C30 (version 3.0).

\begin{tabular}{|c|c|c|c|c|c|c|}
\hline & $\mathrm{N}$ & Mean & Median & Standard deviation & Min & $\operatorname{Max}$ \\
\hline \multicolumn{7}{|c|}{ Global health status } \\
\hline Global quality of life & 27 & 62.346 & 66.667 & 15.907 & 33.33 & 83.33 \\
\hline \multicolumn{7}{|c|}{ Functioning scales } \\
\hline Physical & 27 & 86.914 & 93.333 & 15.412 & 46.67 & 100.00 \\
\hline Role & 27 & 91.358 & 83.333 & 8.486 & 83.33 & 100.00 \\
\hline Social & 27 & 62.346 & 66.667 & 15.739 & 33.33 & 100.00 \\
\hline Cognitive & 27 & 100.00 & 100.00 & 0.00 & 100.00 & 100.00 \\
\hline Emotional & 27 & 73.457 & 75.000 & 19.480 & 41.67 & 100.00 \\
\hline \multicolumn{7}{|c|}{ Symptom scales } \\
\hline Fatigue & 27 & 34.156 & 33.333 & 20.884 & 0.00 & 77.78 \\
\hline Nausea and vomiting & 27 & 3.704 & 0.00 & 13.344 & 0.00 & 66.67 \\
\hline Pain & 27 & 47.531 & 33.333 & 35.417 & 0.00 & 100.00 \\
\hline \multicolumn{7}{|c|}{ Independent items } \\
\hline Dyspnea & 27 & 0.00 & 0.00 & 0.00 & 0.00 & 0.00 \\
\hline Sleep disturbance & 27 & 6.1728 & 0.00 & 18.575 & 0.00 & 66.67 \\
\hline Appetite loss & 27 & 1.235 & 0.00 & 6.415 & 0.00 & 33.33 \\
\hline Diarrhea & 27 & 20.988 & 0.00 & 27.962 & 0.00 & 100.00 \\
\hline Constipation & 27 & 1.235 & 0.00 & 6.415 & 0.00 & 33.33 \\
\hline Financial impact & 27 & 97.531 & 100.00 & 8.896 & 66.67 & 100.00 \\
\hline
\end{tabular}

Concerning functional outcome, Sexual complications were found in 11 patients (40.74\%) with 7 cases of erectile dysfunction (25.92\%) and 4 cases of vaginal dryness with dyspareunia (14.81\%). Four patients (14.81\%) presented urinary disorders with 3 cases of urinary incontinence $(11.11 \%)$ and one case (3.7\%) of enuresis.

The main limitation of this study is related to the retrospective patient's selection.

\section{Discussion}

We conducted this study with the aim of determining the survival of patients after rectal cancer surgery and their QoL.

With 68 cases over a 10-year period, this study tends to corroborate the low incidence of rectal cancer in Africa; previous African studies have reported annual incidence ranging from 3.11 to 9.66 cases [9] [10] [16] [25] [26]. However, in the absence of national cancer registries in most of these countries, lack of data collection/under-reporting and the preponderant place of traditional medicine, we think that these incidences are underestimated.

This study confirms that rectal cancer in Africa affects more male than female [10] [16] [25] [26] [27] and most often young adults with a mean age under 50 
years [9] [10] [16]. In western reports, the mean age of patients affected by rectal cancer is around 65 years [28] [29], even if rectal cancer incidence rates increased by $2.3 \%$ to $3.2 \%$ per year in adults ranging in age from 20 to 54 years since past decades [22]. We agree with Cronje et al. [12] that a genetic component in the pathogenesis of rectal cancer can be advocated in young black patients. In fact, they demonstrate that, most young patients ( $<50$ years) with rectal cancer were significantly black than white $(\mathrm{p} \leq 0.001)$ and loss of mismatch repair protein was more evident in black than in whites. However, further studies are needed to prove this hypothesis.

The survival of patients after rectal cancer surgery in our study was poor, with a 5 -year survival of $21.87 \%$. This result is similar to those reported in others African studies with a 5-year survival rate ranging from $3 \%$ to $22 \%$ [16] [30] [31]. Delayed diagnosis, limited accessibility to perioperative radiotherapy/chemotherapy and limited technical platform are possible explanations of these bad results.

Indeed, as in other malignant tumors, the diagnosis of rectal cancer is made late in our context with a predominance of advanced stages; in our study, $63.23 \%$ of patients presented with locally advanced/metastatic forms (stage IIC to IV). The average time from onset of symptoms to diagnosis was 9 months in a similar setting [30].

The therapeutic paths of African subjects are often long and tortuous before they are received in a "western hospital" environment, recourse to marabouts and traditional healers being the first reflex. The identification of absence of schooling was statistically linked to an increased risk of death, thus finds an avenue of explanation. In the case of rectal cancer, tenesmus has been identified as a sign of a locally advanced stage [32], and is related to a bad prognosis in our study.

Poverty and the absence of a national health insurance system can also explain the diagnostic delay and the poor accessibility of our patients to perioperative chemotherapy/radiotherapy. In our context, patients must pay directly out of their pockets, all the costs relating to their care. It's therefore understandable that chemotherapy and/or radiotherapy protocols are beyond the reach of most of them. In this study, neoadjuvant and adjuvant treatments were administered to only $20.6 \%$ and $22.01 \%$ of patients respectively and only one of them received radiotherapy. Similar results are reported in African studies [9] [10] [14] [15] [16] [25]. In our country there exist only one radiotherapy department and it is not located in the capital of the country where our study took place. Our patients, with predominant advanced disease should benefit from down staging prior to surgery as recommended [13]. We identified postoperative chemotherapy $(\mathrm{p}=0.015)$, surgical site infection $(\mathrm{p}=0.003)$ and postoperative bowel obstruction $(\mathrm{p}=0.015)$ as independently associated with a diminished survival. In high-income countries, with screening programs and an adequate technical platform, 5 -year survival rates varying from $54.4 \%$ to $73 \%$ have been reported [33] [34] [35].

This study assessed prospectively the QoL of patients after rectal cancer sur- 
gery. The overall QoL of patients were good, and patients undergoing abdominoperineal resection (with a permanent stoma) did not have a poor QoL than those undergoing an anterior rectal resection. If some studies demonstrate that abdominoperineal amputation with a permanent stoma compromises patients' QoL [13] [32] [33], it's known that there is no difference in QoL between sphincter-saving procedures and abdominoperineal extirpation [34] [35]. To the best of our knowledge, this study is the first to assess the QoL of patients after rectal cancer surgery in our country. Due to the absence of a national insurance policy and the low-income context, it's not surprising that rectal cancer surgery had a negative financial impact on almost all of our patients. The instauration of a universal health coverage system in our country and in black Africa in general could be a solution.

The prevalence of sexual dysfunction was high in our series (40.74\%). Sexual problems after rectal cancer surgery are common; females are more affected than males [23]. We think that sexual dysfunction could have a negative impact on patients' QoL, especially regarding their young age in our series. Unfortunately, sexual (and urinary) complications are not specifically mentioned as item in the EORTC QLQ C30. More attention should be drawn in this topic in further studies.

The main limitation of this study is related to the retrospective identification of operated patients. Thus, of the 105 patients identified as having been operated on for a rectal tumor, only $68(64.7 \%)$ were collected. The lack of computerization of medical files in our context, associated with non-rigorous archiving of the (paper) files used, leads to a significant loss of data. Our sample is therefore relatively small.

\section{Conclusion}

There is a low hospital incidence of rectal cancer in our context; young adults under 50 years are more affected. The 5-year survival after rectal cancer surgery is poor. QoL of living patients is good despite a high prevalence of sexual dysfunction.

\section{Authors' Contribution}

GAB conceited the study. EPS and GBM collected the data, which were analyzed by JYF, YMEB and DBB. GAB and EPS wrote the paper. DBB, OO and AE revised and edited the work. MAS gave the final approval.

\section{Conflicts of Interest}

The authors declare no conflicts of interest regarding the publication of this paper.

\section{References}

[1] Siegel, R.L., Miller, K.D., Goding Sauer, A., Fedewa, A., Butterly, L.F., Anderson, 
J.C., et al. (2020) Colorectal Cancer Statistics, 2020. A Cancer Journal for Clinicians, 70, 145-164. https://doi.org/10.3322/caac.21601

[2] Bray, F., Ferlay, J., Soerjomataram, I., Siegel, R.L., Torre, L.A. and Jemal, A. (2018) Global Cancer Statistics 2018: GLOBOCAN Estimates of Incidence and Mortality Worldwide for 36 Cancers in 185 Countries. A Cancer Journal for Clinicians, 68, 394-424. https://doi.org/10.3322/caac.21492

[3] Lambert, R. (2012) Variations du risque de cancer colorectal selon les ressources économiques. Cancéro Digest, 4, 140-144. https://doi.org/10.4267/2042/47607

[4] Bagnaka Eloumou, S.A.F., Bekolo Nga, W.T., Kenfack, G.U., Touko, L., Malongue, A., Tzeuton, C., et al. (2020) Facteurs pronostiques du cancer colorectal au Cameroun. Health Sciences and Disease, 21, 90-94.

[5] Herman, A.M., Hawkins, A.T., Misso, K., Issangya, C., Tarmohamed, M., Mremi, A., et al. (2020) Colorectal Cancer in Northern Tanzania: Increasing Trends and Late Presentation Present Major Challenges. JCO Global Oncology, 6, 375-381. https://doi.org/10.1200/JGO.19.00301

[6] Irabor, D.O., Oludolapo Afuwape, O. and Ayandipo, O.O. (2014) The Present Status of the Management of Colon and Rectal Cancer in Nigeria. Journal of Cancer Research, 1, Article ID: 267190. https://doi.org/10.1155/2014/267190

[7] Guingané, A.N., Sombié, R.A. and Bougouma, A. (2014) Les tumeurs malignes anorectales en milieu hospitalier à Ouagadougou: aspects épidémiologiques et diagnostiques. The Pan African Medical Journal, 18, Article No. 26.

[8] Takongmo, S., Essame-Oyono, J.L., Binam, F., Sadou, H. and Malonga, E.E. (2000) Les cancers colo-rectaux du sujet de moins de 40 ans à yaoundé : des particularités anatomo-cliniques? Medecine d'Afrique Noire, 47, 101-104.

[9] Ngo-Nonga, B., Mouafo Tambo, F., Farikou, I., Fouda, J.P., Ngowe Ngowe, M., Bahebeck, J., et al. (2011) Problématique du traitement du cancer rectal localement invasif dans un pays avec des ressources médicales limitées. Louvain Médical, 130, 349-352.

[10] Hama, Y., Rabiou, S., Efared, B., Sani, R., Harouna, Y.D. and Nouhou, H. (2017) Cancer du rectum et pauvreté : Une fracture médicale! Journal Africain d Hépato-Gastroentérologie, 11, 164-167.

[11] Belhamidi, M.S., Sinaa, M., Kaoukabi, A., Krimou, H., Menfaa, M., Sakit, F., et al. (2018) Profil épidémiologique et anatomopathologique du cancer colorectal: à propos de 36 cas. The Pan African Medical Journal, 30, Article No. 159. https://doi.org/10.11604/pamj.2018.30.159.15061

[12] Cronjé, L., Paterson, A.C. and Becker, P.J. (2009) Colorectal Cancer in South Africa: A Heritable Cause Suspected in Many Young Black Patients. South African Medical Journal, 99, 103-106.

[13] Feeney, G., Sehgal, R., Sheehan, M., Hogan, A., Regan, M., Joyce, M., et al. (2019) Neoadjuvant Radiotherapy for Rectal Cancer Management. World Journal of Gastroenterology, 25, 4850-4869. https://doi.org/10.3748/wjg.v25.i33.4850

[14] Gbessi, D.G., Seto, D.M., Atindehou, S.L., Lawani, I., Azon-Kouanou, A., Gnangnon, F., et al. (2015) Facteurs pronostiques de mortalité précoce dans les cancers colo-rectaux au Bénin. Benin Medical Care, 59, 21-26.

[15] Diémé, E.G.P.A., Tine, M.M.C., Sall, I., Ndiaye, R., Diouf, M., Fall, O., et al. (2019) Prise en charge des cancers colorectaux en occlusion à l'hôpital principal de Dakar : à propos de 37 cas. Mali Médical, 34, 40-47.

[16] Coulibaly, B., Traoré, D., Togola, B., Dembélé, M., Traoré, I., Ongoïba, M., et al. 
(2012) Cancer du rectum: Aspects épidémio-cliniques, traitement chirurgical et pronostic. Mali Médical, 27, 7-10.

[17] Parker, R.K., Mwachiro, M.M., Ranketi, S.S., Mogambi, F.C., Topazian, H.M. and White, R.E. (2020) Curative Surgery Improves Survival for Colorectal Cancer in Rural Kenya. World Journal of Surgery, 44, 30-36. https://doi.org/10.1007/s00268-019-05234-1

[18] Qiu, Y., Liu, Q., Chen, G., Wang, W., Peng, K., Xiao, W., et al. (2016) Outcome of Rectal Cancer Surgery in Obese and Nonobese Patients: A Meta-Analysis. World Journal of Surgical Oncology, 14, Article No. 23. https://doi.org/10.1186/s12957-016-0775-y

[19] Ballian, N., Yamane, B., Leverson, G., Harms, B., Heise, C.P., Foley, E.F., et al. (2010) Body Mass Index Does Not Affect Postoperative Morbidity and Oncologic Outcomes of Total Mesorectal Excision for Rectal Adenocarcinoma. Annals of Surgical Oncology, 17, 1606-1613. https://doi.org/10.1245/s10434-010-0908-4

[20] Mrak, K., Eberl, T., Fritz, J. and Tschmelitsch, J. (2012) Influence of Body Mass Index on Postoperative Complications after Rectal Resection for Carcinoma. Southern Medical Journal, 105, 493-499. https://doi.org/10.1097/SMJ.0b013e3182666f09

[21] Beyrouti, M.I., Abbes, I. and Affes, N. (2003) Les facteurs prédictifs de récidive loco-régionale des cancers rectaux. Randomization and Trial Supply Management, 5, 17-24.

[22] Marquis, R., Lasry, J.C., Heppell, J., Potvin, C., Palardeau, M. and Robidoux, A. (1992) Qualité de vie des patients opérés à visée curative pour un cancer du rectum. Annales de Chirurgie, 46, 830-838.

[23] Istvan, G., Lazorthes, F., Cherubin, M., Buisson, T., Gamagani, R. and Chiotasso, P. (1997) Préservation de l'innervation sexuelle dans la chirurgie des cancers du rectum. Annales de Chirurgie, 51, 678-681.

[24] Bouchot, O., Boullanger, P., Casse, C., Labat, J.J. and Buzelin, J.M. (1995) Les complications sexuelles de la chirurgie rectale chez l'homme: Conseils pratiques pour la prise en charge. $H G O D, 2,497-505$.

[25] Mesli, S.N., Regagba, D., Tidjane, A., Benkalfat, M. and Abi-Ayad, C. (2016) Analyse des facteurs histo-pronostiques du cancer du rectum non métastatique dans une série ouest Algérienne de 58 cas au CHU-Tlemcen. The Pan African Medical Journal, 24, Article No. 5. https://doi.org/10.11604/pamj.2016.24.5.8580

[26] Dieng, M.M., Gaye, P.M., Diouf, D., Ka, S., Fall, M.C.G., Ba, B., et al. (2019) La radiothérapie des cancers du rectum: Etude monocentrique dans un Institut Africain de Lutte contre le Cancer, Institut Joliot Curie de Dakar au Sénégal. Rafmi, 6, 33-42.

[27] El Housse, H., Ajbara, W., Amsaguine, S., El Amrani, N., Drissi, H., Ahallat, M., et al. (2015) Profils épidémiologique et anatomoclinique d'une population marocaine atteinte de cancer colorectal. Journal Africain du Cancer, 7, 95-99. https://doi.org/10.1007/s12558-014-0352-3

[28] Babaei, M., Jansen, L., Balavarca, Y., Sjövall, A., Bos, A. and Van de Velde, T. (2018) Neoadjuvant Therapy in Rectal Cancer Patients with Clinical Stage II to III across European Countries: Variations and Outcomes. Clinical Colorectal Cancer, 17, e129-e142. https://doi.org/10.1016/j.clcc.2017.09.002

[29] Siegel, R.L., Fedewa, S.A., Anderson, W.F., Miller, K.D., Ma, J., Rosenberg, P.S., et al. (2017) Colorectal Cancer Incidence Patterns in the United States, 1974-2013. J Journal of the National Cancer Institute, 109, Article ID: djw322. https://doi.org/10.1093/jnci/djw322 
[30] Benamr, S., Mohammadine, E., Essadel, E., Lahlou, K., Taghy, A., Chad, B., et al. (1998) Le cancer du rectum chez le sujet jeune: Facteurs de mauvais prognostic. Médecine du Maghreb, 68, 22-26.

[31] Casanelli, J.M., Blegole, C. and Moussa, B. (2005) Cancer du rectum: Aspects épidemiologiques, cliniques et thérapeutiques à propos de 16 cas au $\mathrm{CHU}$ de Treichville. Mali Médical, 4, 21-23.

[32] Minsky, B.D., Rödel, C.M. and Valentini, V. (2016) Rectal Cancer. In: Gunderson, L.L. and Tepper, J.E., Eds., Clinical Radiation Oncology, 4th Edition, Amsterdam, Elsevier, 992-1018. https://doi.org/10.1016/B978-0-323-24098-7.00051-4

[33] Wibe, A., Møller, B., Norstein, J., Carlsen, E., Wiig, J.N., Heald, R.J., et al. (2002) Norwegian Rectal Cancer Group. A National Strategic Change in Treatment Policy for Rectal Cancer-Implementation of Total Mesorectal Excision as Routine Treatment in Norway. A National Audit. Diseases of the Colon \& Rectum, 45, 857-866. https://doi.org/10.1007/s10350-004-6317-7

[34] Joseph, D.A., Johnson, C.J., White, A., Wu, M. and Coleman, M.P. (2017) Rectal Cancer Survival in the United States by Race and Stage, 2001 to 2009: Findings from the CONCORD-2 Study. Cancer, 123, 5037-5058.

https://doi.org/10.1002/cncr.30882

[35] Watanabe, J., Shoji, H., Hamaguchi, T., Miyamoto, T., Hirano, H., Iwasa, S., et al. (2019) Chemoradiotherapy for Local Recurrence of Rectal Cancer: A Single Center Study of 18 Patients. In Vivo, 33, 1363-1368. https://doi.org/10.21873/invivo.11612 